\title{
Understanding the pathogenesis of peripartum heart failure in northern Nigeria based on interactions of external heat stress conditions with coenzyme Q10, selenium and magnesium - shared biochemical similarities with the pathogenesis of thyroid disease
}

\author{
Moncayo $\mathrm{R}^{*}$ and Moncayo $\mathrm{H}$ \\ Department of Nuclear Medicine, Medical University of Innsbruck, Innsbruck, Austria
}

\begin{abstract}
A recent publication in the Canadian Journal of Cardiology has described a case of post-partum heart failure with concomitant hyperthyroidism due to thyroiditis. In an accompanying Editorial a potential multisystemic nature of both entities was proposed. The hypothesis motivated us to review the relevant literature and to compare it with our clinical and biochemical concepts of benign thyroid disease. Combining clinical experience in thyroid diseases and deductive analysis of available biochemical literature we have been able to identify common elements in thyroiditis and post peripartum heart failure that relate them to the basic mechanisms of heat shock response. In peripartum heart failure, as seen in northern Nigeria, the connection to heat shock is more evident since a special ritual in the post-partum period in this region consists of exposing the women to whole body heat by means of hot baths $\left(82^{\circ} \mathrm{C}\right)$. In thyroid disease heat exposure prior to functional alteration can be found in single cases. Heat exposure in living systems leads to a heat shock reaction that involves several functional pathways starting with heat shock factor 1 , STAT3, and the heat shock proteins (hsp). Among the hsp, hsp90 requires ATP to exert its action, i.e. the oxidative phosphorylation respiratory chain (OXPHOS) must be functioning. Due to the known thermolability of Coenzyme Q10 (CoQ10), OXPHOS will be altered under heat stress conditions resulting in lower levels of ATP and a higher production of reactive oxidative substances (ROS). The source of ROS can be localized to Complex I, where also CoQ10 is found. Additional deficiency conditions of magnesium and selenium will contribute to an ineffective OXPHOS and to decreased protection against ROS, respectively. Finally, low levels of ATP will affect its function as a hydrophore, i.e. involved in maintaining cellular solubility. Potential contributing factors to low magnesium and low CoQ10 levels is stress. We propose that the link between thyroid and heart disease lies in the common biochemical deficiency condition involving CoQ10, selenium and magnesium. Heat shock can alter the function of Complex I of OXPHOS due to the known thermolability of CoQ10 and low levels of CoQ10 can consequently result in ROS production. Decreased ATP production will affect cell solubility and the action of some hsp components. Altered proteins will induce the unfolded protein reaction, where also ATP supply is necessary. This hypothesis remains to be confirmed by clinical research and biochemical determinations in the field of peripartum heart failure.
\end{abstract}

\section{Introduction}

The June 2019 issue of the Canadian Journal of Cardiology published a single case report of post-partum heart failure with concomitant hyperthyroidism due to thyroiditis [1]. In an accompanying Editorial, Tremblay-Gravel and Pacheco referring to a related entity, i.e. peripartum cardiomyopathy, proposed a yet undefined landscape of multisystemic nature behind both entities which deserved to be investigated [2]. They expected that potential therapeutic points could be identified. At the present time, the only common biochemical finding in both diseases could be low selenium levels $[3,4]$. This biochemical feature was the starting point for our clinical research on benign thyroid disease in 2005. Through a series of subsequent observational studies, we have recognized that selenium deficiency is not the single "silver bullet" in the pathogenesis of thyroid disease. Our present concept considers benign thyroid disease to be the consequence of a complex biochemical deficiency condition involving magnesium, selenium and coenzyme Q10 (CoQ10), being indeed a multisystemic alteration [4-7]. The scientific interest on selenium deficiency in relation to peripartum cardiomyopathy in Nigeria has resulted in the launching of a registry project aiming to evaluate the potential utility of selenite administration [8]. The aim of this review was to analyze peripartum heart failure as it was originally described in Nigeria from the standpoint of a heat shock condition. The obvious connection to heat shock comes from the ritual use of hot, humid baths in the post-partum period [9]. While heat exposure is not a recognized classical cause leading to thyroid disease, we have recently made single observations that relate this factor to hyperthyroidism. Using power Doppler sonography [10] distinct changes in thyroid perfusion, that correspond to deficiency of coenzyme Q10 (CoQ10), can be found. CoQ10 deficiency can also be encountered during pregnancy, in the

${ }^{\star}$ Correspondence to: Moncayo R, Department of Nuclear Medicine, Medical University of Innsbruck, WOMED, Karl-Kapferer-Strasse 5, 6020 Innsbruck, Austria, E-mail: r.moncayo@chello.at

Key words: thyroiditis, magnesium, selenium, coenzyme Q10, post-partum, heart failure, heat stress, heat stress proteins, mitochondria, endoplasmic reticulum, unfolded protein response

Received: February 04, 2020; Accepted: February 19, 2020; Published: February 26,2020 
Moncayo R (2020) Understanding the pathogenesis of peripartum heart failure in northern Nigeria based on interactions of external heat stress conditions with coenzyme Q10, selenium and magnesium - shared biochemical similarities with the pathogenesis of thyroid disease

post-partum as well as in patients with concomitant signs of cardiac insufficiency at the time of the initial diagnosis. Since blood levels of CoQ10 have not been subject of scientific investigation in postpartum heart failure we will rely on a theoretical analysis of the heat shock response in order to attempt to decipher the multisystemic nature of this entity. We will discuss features shared by post-partum heart failure and thyroiditis in the light of the original [11] and present descriptions of the heat shock reaction [12]. The potential general applicability of this hypothesis will be illustrated by looking at heat stress in the general working population and especially in relation to competitive sport venues.

\section{Concise description of the WOMED model of benign thyroid disease}

Our clinically oriented research on benign thyroid disease since many years has allowed us to propose a disease mechanism of acquired mitochondrial dysfunction which we called the WOMED model [6]. The model is based on the identification of changes of thyroid morphology and perfusion that correspond to a basic mechanism of thyroid inflammation, i.e. thyroiditis, which in turn shows a clear relation to specific biochemical deficiencies affecting blood levels of selenium [4], magnesium and CoQ10 [6,13]. The fundamental examination of patients with suspected thyroid disease is done with power Doppler sonography [10]. This simple imaging tool allows the clinician to recognize the deficiency situations based on the following perfusion patterns: 1) in magnesium deficiency there is a diffuse, spot-like increase in perfusion; 2) in CoQ10 deficiency vascularity is increased and the vessels show an increased diameter; 3 ) in selenium deficiency fibrosis of the thyroid can be found. When these basic biochemical deficiencies have been corrected by supplementation, the morphological and perfusion alterations of the thyroid gland revert to normal [7]. Cases that present a fibrosis of the thyroid will not show improvement. We have learned that selenium supplementation alone cannot improve the changes seen in the thyroid [14]. Through a trial and error approach together with scientific deduction we have designed our current supplementation protocol to include the following elements: 1) pure magnesium citrate at a dose of $400 \mathrm{mg}$ capsules 6-8 times daily (8.4 - $11.2 \mathrm{mmol}$ of elemental magnesium); 2) selenomethionine $200 \mu \mathrm{g} / \mathrm{d}$, and 3) CoQ10 30 to $60 \mathrm{mg} / \mathrm{d}$ [7]. Iron substitution will be added when ferritin levels are below $20 \mathrm{ng} / \mathrm{ml}$. Most compliant patients report an improvement in their general condition, less tiredness, improved sleep and better physical achievement capacity within 3 to 6 months. Supplementation must be maintained until the thyroid vascularity changes return to normal, otherwise a rebound of the condition can occur. Severe cases presenting concomitantly characteristics of the burn-out syndrome [15] need a longer period of supplementation and might also profit from the addition of an adaptogen in the form of an herbal supplement [16,17]. One drawback of this supplementation approach is the lack of financial refund from the state medical insurance system.

On biochemical terms our model considers that the elements mentioned above contribute to the maintenance of normal mitochondrial function and in the end of energy production [18]. The interactions can be described as follows: 1) magnesium is essential for ATP production departing from Mg-ADP [19,20]; 2) selenoproteins are needed for anti-oxidative protection especially via glutathione peroxidase (GPX) as well as for thyroid hormone conversion in the periphery [21]; 3) CoQ10 is needed for the correct function of Complex I of OXPHOS [22,23] and has a clear influence on vascular morphology
[24] and oxidative stress [25]; 4) iron is needed for the synthesis of iron-sulfur clusters [26] which support many mitochondrial functions and specifically those of Complex I [27,28]; 5) intracellular magnesium correlates with selenium levels; and 6) conservation of CoQ10 via invivo recycling is a process that needs selenium in the form thioredoxin reductase (TrxR1) [29].

\section{Implicit relation between peripartum heart failure in nigeria and heat stress}

The clinical picture of peripartum heart failure has been described since more than a century. In 1849 Ritchie reported the case of peripuerperal heart affections (Case 6 of the series in [30]). Porak described a similar situation in 1880 [31]. In 1937 Gouley reviewed the literature available at that time commenting on "an idiopathic myocardial lesion associated with the puerperium" [32]. In 1974 a detailed clinical description of peripartum cardiac failure in Nigeria was provided by Davidson, Trevitt and Parry [33]. The authors described a potential connection to heat stress by stating the following: "Peripartum cardiac failure (PPCF) is common in Zaria, in northern Nigeria, but has not been described elsewhere in Nigeria except in Ibadan. The geographic origin of a series of 224 patients with PPCF was studied in Zaria, and a survey of the syndrome as seen in hospitals and by physicians in the northern states of Nigeria was carried out; information was also gathered from medical and nursing students from various tribal groups in the same area. It was found that PPCF is only common in the areas of Hausa majority, mostly around Zaria and Malumfashi, where the postpartum practices of taking hot baths, lying on a hot bed, and taking large amounts of kanwa (a lake-salt rich in sodium) are pursued with great vigour. These customs may impose a critical load on a vulnerable myocardium, and it seems that tribe and tradition could well explain the high incidence of PPCF around Zaria”. At that time the critical load was not further characterized. The following quotation is taken from another description of this custom [34]. "There is an ancient area in Northern Nigeria inhabited mainly by traditionally-oriented natives, mostly Hausas and Fulanis. Women of these tribes traditionally deliver their babies at home under the care of midwives, using hospitals only as a last resort. Since cold is thought to carry puerperal illnesses, it is the practice among these people to initiate hot baths for mothers immediately after delivery. 2 major complications of the practice are peripartal cardiac failure and burns. The case is reported of 1 woman who was taken to a hospital with superficial burns as a result of the practice. She had continued to follow this practice despite earlier experience of cardiac failure by doing so. It may be easier to persuade these natives to use slightly colder water than to give up completely this entrenched practice.” In 1977 Fillmore and Parry described the evolution of peripartal heart failure and concluded that: "It is our postulate that many of our patients develop failure through a combination of the hot, humid weather aggravated by the high sodium intake, the prolonged heating, and the repeated hot baths" [35]. In a study by Ford et al. one can observe the construction of a traditional hot bath (Figure 2) [36]). According to Mabogunje the temperature in this setting can reach $82^{\circ} \mathrm{C}$ [37]. In addition to the hot baths the women lie on mud beds kept heated by fireworks for 40 to 120 days post-partum [38]. Similar information was provided per email by Dr. Ayyuba Rabiu as of August 2019 as follows: "The water usually boils before the hot bath". Recent epidemiological analyses in 2006 and 2007 have shown that women in Nigeria are still following these practices in a high percentage of cases [39,40]. In an updated account of heart failure in Nigeria in 2018 Saitu et al. described peripartum cardiomyopathy as the most frequent condition behind heart failure [41]. 
Moncayo R (2020) Understanding the pathogenesis of peripartum heart failure in northern Nigeria based on interactions of external heat stress conditions with coenzyme Q10, selenium and magnesium - shared biochemical similarities with the pathogenesis of thyroid disease

\section{Selected basic historical observations on heat stress contributed by Ritossa and complemented by the early findings of szent-györgy on muscular work}

The concept of heat shock started from observations made by Ferruccio Ritossa in 1962 [11]. Ritossa came from the Laboratorio Internazionale di Genetica e Biofisica, Napoli, Italy and was participating in a course dealing with the biological action of radiations held at the Genetics Institute in Pavia and organized by Adriano Buzzati Traverso. His original publication had the title: "A new puffing pattern induced by temperature shock and DNP in drosophila". In his experiments the temperature was set at $30^{\circ}$, and the exposure time to 30 minutes. Ritossa also investigated the actions of 2 substances known to interfere with the function of oxidative phosphorylation (OXPHOS), namely salicylate and 2-4 dinitrophenol (DNP). Ritossa was able to demonstrate that both substances could also produce the heat effect. His own account 34 years later [42] included the following description: "I cannot remember whether it was John Pulitzer or Inge or Clara Ghini or Giordano who shifted the temperature of my incubator, but one day I noticed a different puffing pattern! I calculated the right conditions for the shift and observed new RNA synthesis. I was impressed by the rapidity with which new RNA was synthesized: just 2-3 minutes! Similar puffs were also present in malpighians and gut polytene chromosomes, while those present before were shut off. Then I remembered the Szent Gyorgyi book and wondered whether heat might destroy the ice structure of water around the proteins of the electron transport chain, which would cause uncoupling of oxidative phosphorylation. I immediately did the experiments and observed that uncouplers of ATPase, such as dinitrophenol and salycilate, as well as recovery from anoxia, induced the activation of the same new genes. It does not matter if this interpretation was true or false; it was a working link between imagination and reality, like love".

The inclusion of elements from the work of Albert Szent-Györgyi extended significantly the original setting of heat shock research. Szent-Gyögyi begins Section 1 of his book defining the central problem as follows: "...how does energy drive life? How does it move the living machine? [43]. He described an experiment where he observed the contractility of a muscle strip taken from the psoas muscle of the rabbit. The muscle strip had been placed in diluted glycerol and kept in deep freeze afterwards. The muscle contracted after bringing the muscle strip to room temperature and adding "a little Mg and ATP". Studies made by Gabai and Kabakov have shown that ATP depletion induced by rotenone, another respiratory inhibitor, is also a situation that induces a stress reaction [44]. When rotenone and thermal treatment were applied at the same time, cell viability decreased significantly. Transient ATP depletion resulted in protein aggregation. These experiments show the important interrelation of ATP with heat shock proteins (hsp). At the same time, it has to be reminded that problems of protein aggregation have to be dealt by the endoplasmic reticulum in the context of the unfolded protein response [45-47], a reaction that also requires ATP [48]. In view of these concepts, we can state that Ritossa observed the effects of an external heat source which led to the heat shock and the unfolded protein reactions. A modern view of heat shock response includes more noxious elements besides heat exposure. Trautinger provided the following description: "All organisms respond to sudden environmental changes with the increased transcription of genes belonging to the family of heat shock proteins (hsps). Hspinducing stress factors include elevated temperatures, alcohol, heavy metals, oxidants, and agents leading to protein denaturation. The induction of heat shock proteins is followed by a transient state of increased resistance to further stress and the heat shock response is generally thought to represent an evolutionary conserved adaptive mechanism to cope with hostile environmental conditions" [49]. Modern knowledge of the complex processes involved in the hsp response describes essential interactions with ATP in the case of ATPdependent hsp chaperones $[12,50]$. Alteration in protein structure will also involve the repair mechanisms of the unfolded protein response [51]. Details of these specific biochemical processes can be found in the cited literature.

\section{A hot look at the environment - some effects of heat stress on mitochondria with special emphasis put on complex I of OXPHOS}

In our opinion, the most compelling evidence on the influence of heat stress on mitochondrial function comes from the known thermolability of Complex I and especially of CoQ10 [52]. Under experimental conditions Pobezhimova et al. have shown that heat stress affects the function of Complex I the main change being the inactivation of Complex I [53]. A similar result of altered function of Complex I through heat exposure has been reported by Ludwig et al. in a system that used beef heart mitochondria [54]. The isolated CoQ10 substance also shows lability in relation to heat stress at $45^{\circ}$ to $55^{\circ} \mathrm{C}$ [55]. A decrease in the levels of CoQ10 will alter and diminish the function of Complex I of OXPHOS. Mitochondria lacking CoQ10 will then produce more ROS. If this occurs in the heart, then heart function will be compromised. Already in 1999 Ide et al. proposed that Complex I could be the source of ROS in the failing heart [56]. The heart is indeed the organ with the highest CoQ10 content in the body and low levels of CoQ10 can consequently affect cardiac function [57]. A similar situation can be expected in conditions such as cardiomyopathy [58]. Recently 2 publications have looked at cardiac disease and heat stress. Ranek et al. described changes of heat shock proteins in heart failure pointing towards the increased expression of hsp70, hsp90 and BAG-3 [59].

In 2012 Iguchi et al. looked at cardiovascular and hormonal changes following heat stress in the form of sitting in a heat stress chamber for 30 minutes at $73^{\circ} \mathrm{C}[60]$. They demonstrated that this stimulus produced an elevation of hsp72 as well as of prolactin. The increase in prolactin levels appears to be related to the endurance capacity in response to exercise under heat conditions [61]. Heat exposure together with muscular activity can also affect magnesium in blood inducing a severe decrease to suboptimal levels [62]. Due to the economic consequences of loss of productivity following heat stress in cattle this phenomenon has been an important research topic in the search for counter action strategies. It has been shown that organic selenium can diminish oxidative changes seen in cows after heat stress [63]. Grazing cattle in summer can present heat stress related alterations in milk production and fertility as well as on hormone parameters [64]. An elegant experimental procedure of heat exposure in the post-partum done with Holstein cows has documented alterations in Complex I of OXPHOS as well as mitochondrial function in general [65]. Christen et al. have investigated the effect of graded heat exposure on the integrity of heart mitochondria and found that mitochondrial function was limited. They considered that Complex I played a pivotal role in the process [66]. Sea species are not free from heat stress due to higher water temperature due to climatic causes. In corals the oxidation of the CoQ pool is considered to be an early biomarker of thermal stress [67]. In tropical reef fishes, high levels of ubiquinol are considered to indicate a high level of protection required against oxidative stress [68]. In short, the take-home message from the data cited above can be stated as 
Moncayo R (2020) Understanding the pathogenesis of peripartum heart failure in northern Nigeria based on interactions of external heat stress conditions with coenzyme Q10, selenium and magnesium - shared biochemical similarities with the pathogenesis of thyroid disease

follows. Heat stress can lead to lower magnesium levels and to elevation of prolactin. Heat stress can affect CoQ10 which will consequently alter and diminish the function of Complex I of OXPHOS. Mitochondria lacking CoQ10 will then produce more ROS. A frequent approach to the administration of CoQ10 is to idealize a single anti-oxidative function of the substance. We prefer to consider CoQ10 as a constituent of Complex I of OXPHOS [69]. Supplementation will restore function and prevent ROS production. In addition to this specific function in OXPHOS, it has been demonstrated that CoQ10 can have a protective effect in situations of burn-induced mitochondrial dysfunction in mouse skeletal muscle [70].

\section{Clinical demonstration of heat and pregnancy influ- ence on thyroid disease}

The following descriptions include single clinical situations of thyroid disease seen recently by us. The common denominator of these cases is the finding of hyper-perfusion of the gland with the pattern that corresponds to CoQ10 deficiency. These sonographic changes have no relation to thyroid antibodies.

Sequential appearance of hyperthyroidism, cerebral and myocardial ischemia and post-partum thyroiditis - our index case for CoQ10 deficiency: The first case of a complex clinical situation involved a young woman who has been examined between 2008 and 2019. This Index Case presented consequently a series of medical conditions including hyperthyroidism, cerebral ischemia, and myocardial infarction. The biochemical determinations detected low levels of magnesium and CoQ10. The first thyroid sonography was done in May 2008 and revealed a hypo-echogeneic gland with massive hyper-perfusion. Supplementation with magnesium and CoQ10 normalized thyroid morphology and function. In 2018 a postpartum thyroiditis with hyperthyroidism and marked magnesium deficiency was diagnosed. On ultrasound the thyroid showed a pronounced diminution of echogenicity together with hyper-perfusion suggestive of CoQ10 deficiency. Since the patient was breast-feeding a combined supplementation was started again using a higher daily dose of magnesium, i.e. $11.2 \mathrm{mmol}$ of elemental magnesium $(\sim 3.2 \mathrm{~g}$ of magnesium citrate). CoQ10 was given at a dose of $30 \mathrm{mg} / \mathrm{d}$. Within 3 months thyroid function, thyroid morphology and perfusion had returned to normal.

(Figure 1) demonstrates the morphology and perfusion of the thyroid as seen in 2008 and 2019 . The thyroid shows now a slightly heterogeneous morphology while perfusion is normal.

Thyroid perfusion changes during pregnancy: One pregnant woman seen between April and August 2019 showed marked changes of perfusion which corresponded to 2 different biochemical settings: magnesium and CoQ10 deficiency (Figure 2).

Hyperthyroidism developing after combined heat and exertional stress: In the past 2 years we have observed a small number of hyperthyroid patients who have initially presented signs and symptoms suggestive of cardiac disease. Laboratory examination showed an elevation of NT-pro-BNP and creatine kinase. Echocardiography did not reveal cardiomyopathy. In one case of a male patient, heat stress

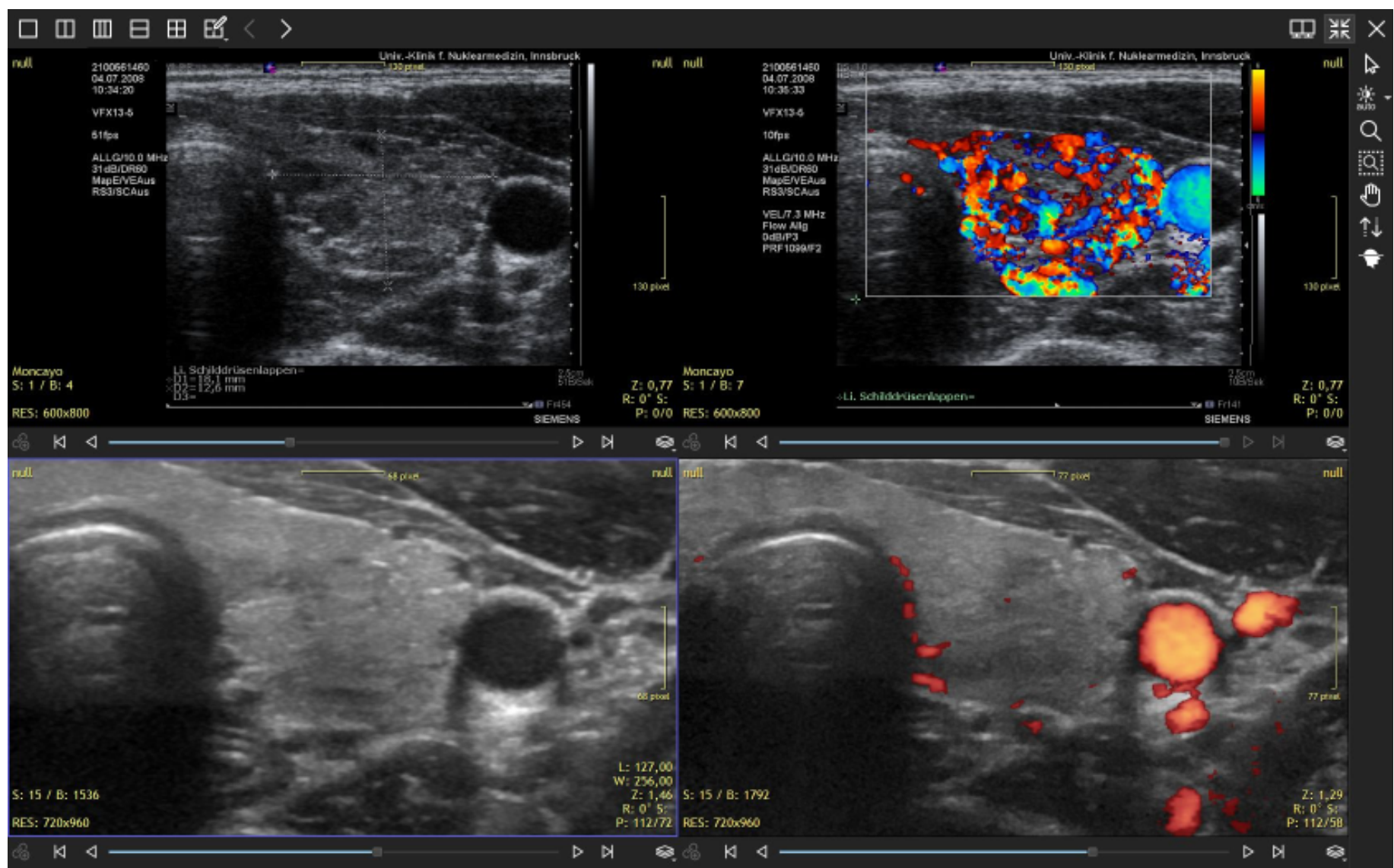

Figure 1. Thyroid sonography with 2 different systems: SIEMENS Antares in 2008 and GE LOGIQ E9 in 2019. The initial alterations showed diminished echogenicity and hyper-perfusion. These changes have disappeared after combined supplementation was started. Currently the patient does not require thyroid medication 
Moncayo R (2020) Understanding the pathogenesis of peripartum heart failure in northern Nigeria based on interactions of external heat stress conditions with coenzyme Q10, selenium and magnesium - shared biochemical similarities with the pathogenesis of thyroid disease

together with intense physical activity (active sports vacation) was the precipitating event (Figure 3). The patient complained of reduced physical capacity almost to the level of physical exhaustion while the time of physical recovery was prolonged. This situation corresponds to the picture seen in heatstroke when vigorous muscle exertion has been made [71]. Heart function was normal.

Postpartum thyroiditis and hyperthyroidism: The sibling of the previous patient (Figure 4) presented a condition of postpartum thyroiditis with hyperthyroidism showing less pronounced changes in thyroid morphology. Signs of CoQ10-associated hyper-perfusion were present. She responded well to supplementation within 3 months.

Chronic relapsing thyroiditis: 3D power Doppler and ${ }^{18}$ F-FDG PET investigation: The first case of thyroiditis which were able to investigate some 15 years ago has shown a course of chronic relapses of the thyroid affection. Every time a relapse occurred, hyper-perfusion of the thyroid with the pattern of CoQ10 deficiency reappeared. In July 2019 a whole body ${ }^{18}$ F-FDG PET examination was requested by her general practitioner. The study revealed that the metabolism of the thyroid and the heart had switched to glycolysis. The patient had no signs of heart disease (Figure 5).
The preceding clinical cases demonstrate the relation between heat exposure, exertion, pregnancy, post-partum and chronic thyroiditis to decreased levels of CoQ10. The association between thyroiditis relapse and ${ }^{18} \mathrm{~F}$-FDG uptake in the heart has not been described before in the literature. A publication from 1992 has shown that low levels of CoQ10 are indeed connected to glycolysis and high lactate levels and that this condition can be corrected by supplementation [72]. In 1997 Sobreira et al. described low activities of Complexes I+II and I+III when CoQ10 levels were below $25 \%$ of normal. Supplementation with CoQ10 resulted in subjective improvement [73]. A single case report on isolated muscular CoQ10 deficiency has also described lower activity of Complex I [74].

\section{The roles of iron, magnesium, selenium and Coenzyme Q10 in heart failure}

Current scientific literature describes specific roles for CoQ10, iron, selenium and magnesium in relation to cardiac function. The following lines will extract some relevant aspects of this relation.

Iron: Iron sulfur clusters $(\mathrm{Fe} / \mathrm{S})$ are essential cellular elements in the cell. These molecules have been investigated since some 70 years [75]. On a theoretical basis, Fe/S could be altered in PPCF since iron

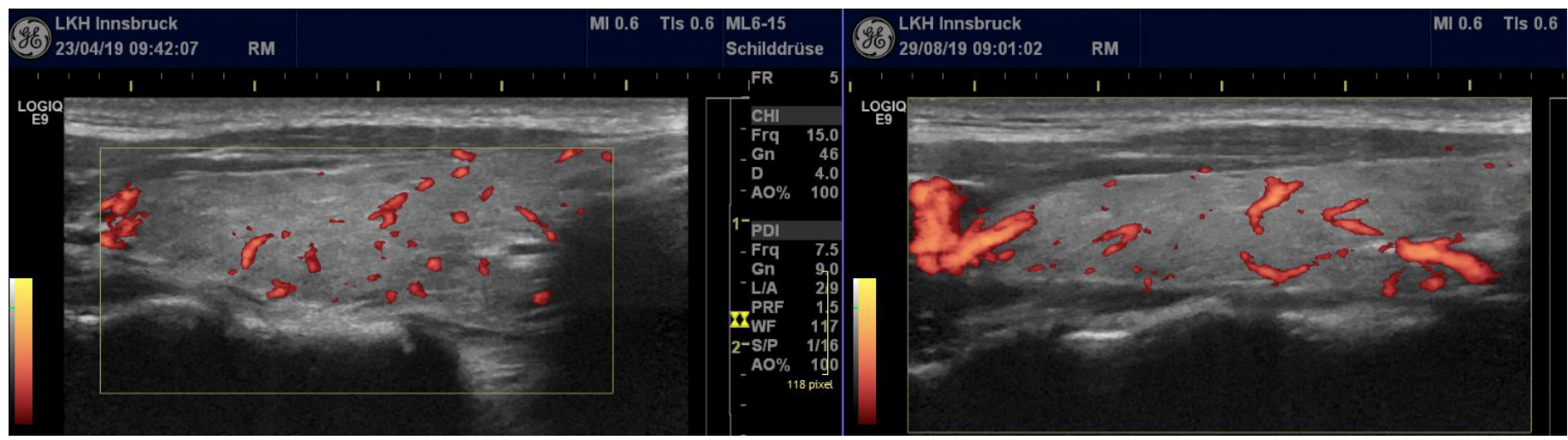

Figure 2. Changes in thyroid perfusion during pregnancy in the same patient. The left panel shows the characteristic spot-like hyper-perfusion due to magnesium deficiency on the 25 th week of pregnancy. The right panel shows the situation 10 weeks later with the typical vessel form seen in CoQ10 deficiency. Thyroid function was normal at both examinations

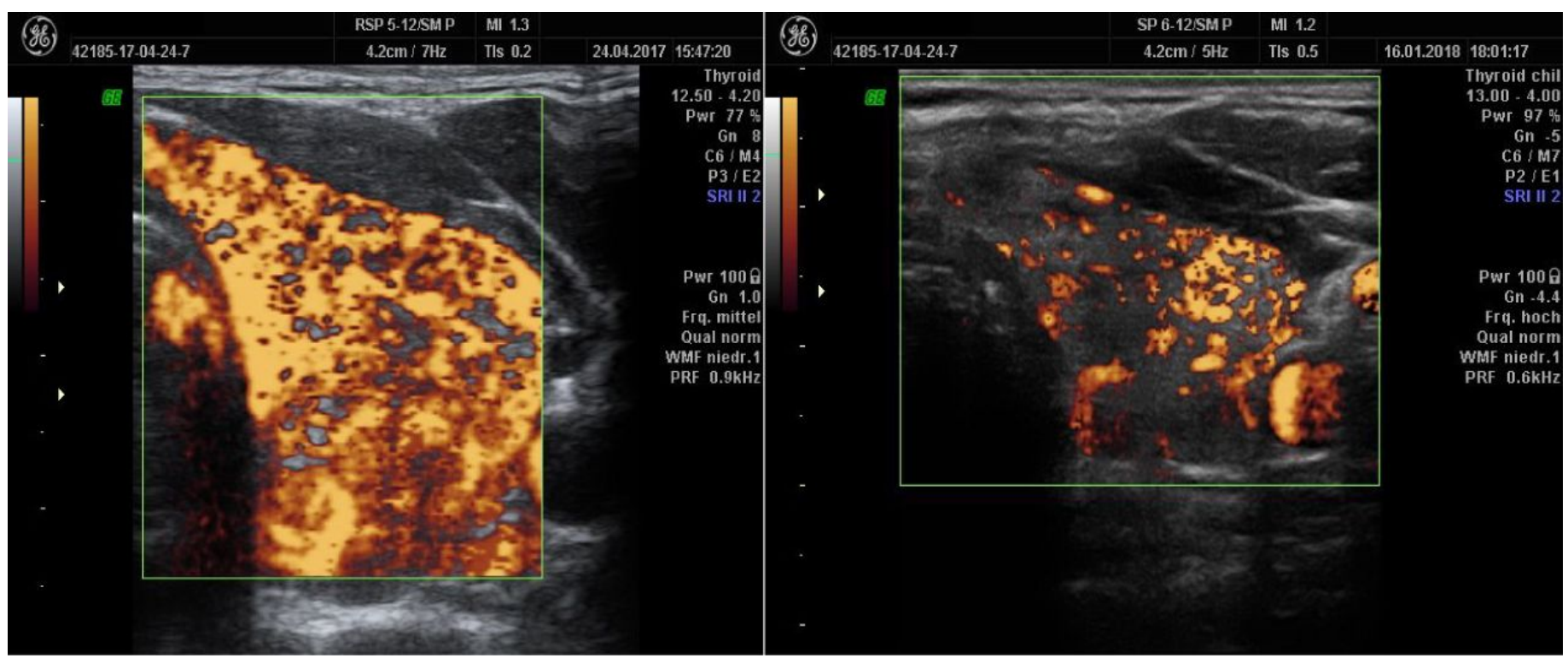

Figure 3. Hyperthyroidism after exertional stress under elevated ambient temperature. A: initial examination showing diffusely increased vascularization. B. In the follow-up examination after 9 months, hyper-perfusion is less pronounced while the thyroid still shows decreased echogenicity 
Moncayo R (2020) Understanding the pathogenesis of peripartum heart failure in northern Nigeria based on interactions of external heat stress conditions with coenzyme Q10, selenium and magnesium - shared biochemical similarities with the pathogenesis of thyroid disease

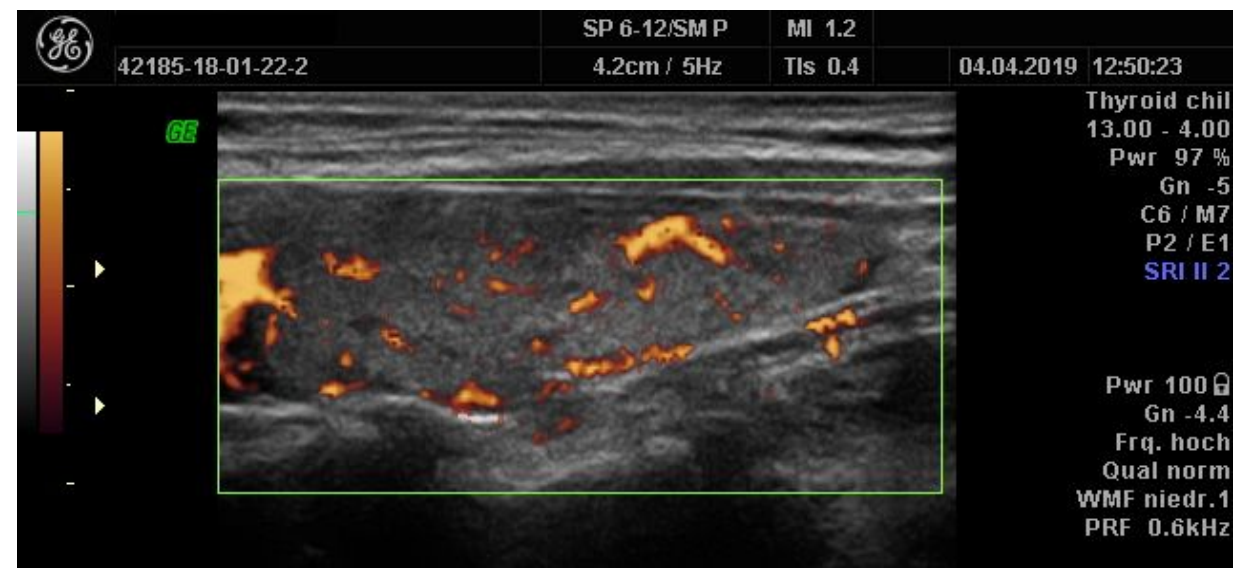

Figure 4. Post-partum thyroiditis with hyperthyroidism. The thyroid is hypo-echogenic. The perfusion pattern corresponds to a combined deficiency of magnesium (small spots) and CoQ10 (wide vessels)

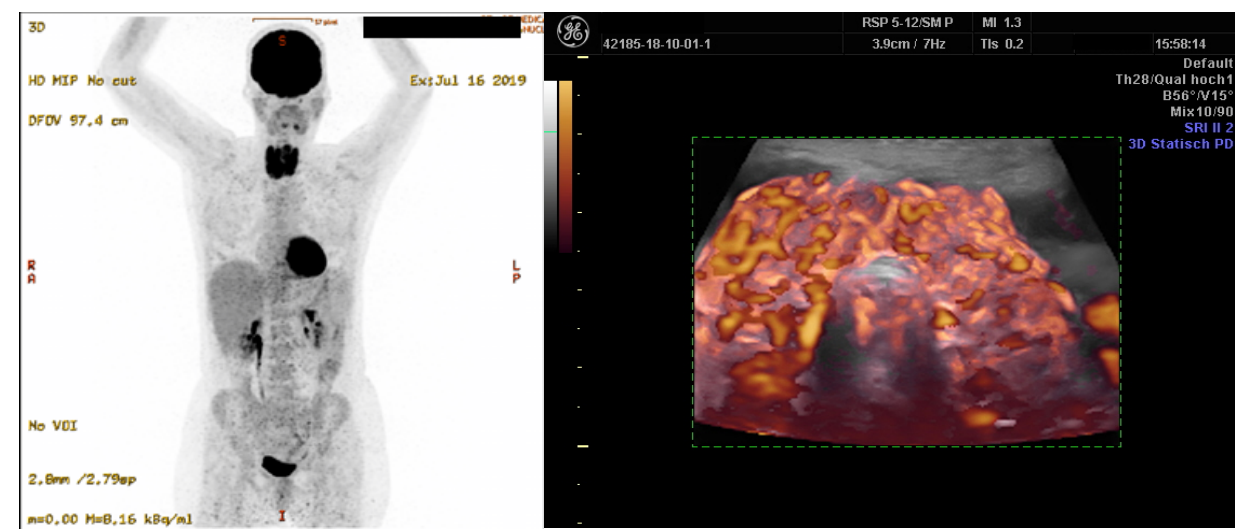

Figure 5. Chronic relapsing thyroiditis showing increased uptake of ${ }^{18} \mathrm{~F}-\mathrm{FDG}$ in the thyroid and heart in a PET examination (left panel). This tracer uptake patterns indicates glycolytic metabolism of the organs. On 3D power Doppler sonography (right panel) one can recognize the marked changes in perfusion with the typical wide vessels that correspond to low CoQ10

deficiency is a frequent condition in pregnant women [76] and iron deficiency is a contributing factor for heart failure [77]. Correction of iron deficiency has been shown to improve heart function $[78,79]$. The contractility of human cardiocytes can be compromised by iron deficiency [80]. The metabolic spectrum and importance of iron in the heart has been extensively reviewed by Paterek, Mackiewicz and Mączewski in 2019 [81]. Mistry et al. have called iron deficiency the underdiagnosed condition in heart failure [82]. To the best of our knowledge, these concepts and therapeutical approaches have not been looked at in PPCF.

Selenium and CoQ10: A series of landmark studies conducted by Cénac and collaborators showed a condition of selenium deficiency in patients with peripartum heart disease $[3,83,84]$. Pregnant women can also present low selenium levels [85] and Afro Americans with heart disease appear to have lower levels of selenium [86]. Studies on peripartum cardiomyopathy have also shown a similar situation $[87,88]$. These results have recently led Karaye to design a new research project aiming at the administration of an inorganic form of selenium [8]. While we have not found any publications dealing with CoQ10 in peripartum heart disease it is important to mention the fact that administering a combined supplementation with selenium and CoQ10 has resulted in improvement in patients with cardiovascular disease $[89,90]$. These publications demonstrate a positive effect of CoQ10 supplementation on heart function showing reduced mortality and reduced proBNP levels [89]: ProBNP levels dropped from 547 to $290 \mathrm{ng} /$ $\mathrm{ml}$. We have to point out the difference of supplementation dose used.
Alehagen et al. administered a much higher dose of CoQ10 as we have, i.e. $200 \mathrm{mg} / \mathrm{d}$. The dose of yeast selenium was $200 \mu \mathrm{g} / \mathrm{d}$., i.e. the same as our dose recommendation. Alehagen et al. did not include magnesium in the therapy. Under experimental conditions it has been shown that low selenium levels will affect the levels of CoQ10 in the liver resulting in CoQ10 deficiency [91,92]. Selenium deficiency has been shown to alter the levels of STAT3 $[93,94]$ which in turn affects the myocardium. Coenzyme Q10 is able to prevent damage to chicken hearts by inducing HSF1 binding activity and Hsp70 expression [95]. The same action can be seen in-vitro [96]. In turn HSF-1 leads to transcriptional regulation of Selenoprotein F when selenium is supplemented [97].

Magnesium: Adamopoulos et al. [98] using a propensity-matched study approach have demonstrated that increased cardiovascular mortality was associated with low serum magnesium. On the other hand, protective effects of sufficient magnesium have been demonstrated in experimental heat shock [99]. In our own studies we have observed a direct correlation between levels of magnesium in whole blood and selenium levels in blood, which are suggestive of a regulatory relationship [13]. The interaction of lactation intensity and potential magnesium depletion has to be mentioned here [100]. The results of the investigations mentioned above point towards an integrated biochemical situation that is needed for maintenance of functionality. Based on the same philosophy we have also applied a systems approach to thyroid disease previously [18]. Currently our investigation of suspected thyroid disease includes the parameters mentioned in this section. Iodine alone is not the answer. 
Moncayo R (2020) Understanding the pathogenesis of peripartum heart failure in northern Nigeria based on interactions of external heat stress conditions with coenzyme Q10, selenium and magnesium - shared biochemical similarities with the pathogenesis of thyroid disease

\section{A "hot" look at the environment - some effects of heat stress on mitochondria}

Bouchama from Saudia Arabia has published a series of studies dealing with heatstroke in humans. In 1995 a historical review on heatstroke included a discussion on the potential role of endotoxins in the disease [101]. Recently the effects of an acute, supra-physiological temperature stress have been looked at the transcriptome level. The test subjects were exposed to a mean temperature of $75^{\circ} \mathrm{C}$ in a sauna. The analysis of blood mononuclear gene expression revealed several patterns of change (Figure 2) [102]. One key finding refers to altered mitochondrial function involving several complexes of the OXPHOS chain including Complex I. Both electron transfer as well as ATP production were repressed. Bouchama et al. also identified an alteration of cytochrome C oxidase which corresponds to Complex IV [103]. Both Complex I and Complex IV depend on iron sulfur clusters for their function. Situations of physical exertion in hot environments with temperatures up to $41.5^{\circ} \mathrm{C}$ can be found in sport activities [104]. Elevated temperature as a source of stress is not only limited to sports. It can also affect everyday activities [105]. Furthermore, these changes are like those seen in heart failure where the function of the OXPHOS chain is altered due to changes in Complex I and V [106]. As a whole ATP production can be disturbed [107]. It has to be kept in mind, that the heat stress response requires sufficient ATP since some hsp are ATP-dependent [12]. Experimental repeated exposure to heat stress can have negative effects on the heat shock response of the heart [108]. The increase of hsp70 levels after heat stress appears to decline with time, thus the susceptibility to heart damage increases with time [109]. This propensity to myocardial damage can be corrected by CoQ10 which has resulted in higher hsp70 levels [96]. In a similar study, the use of the selenium analog ebselen resulted in improved expression of hsp70 which in turn was associated with a reduced size of myocardial infarct [110]. In a recent epidemiological analysis Wang et al. described an association between previous heat stress situations and CVD [111]. Mechanisms leading to these changes were not discussed, however they imply that an altered biochemical system might have remained. The administration of CoQ10 has been shown to be beneficial for patients with heart disease. Folkers et al. demonstrated this rationale in 1985 [112]. "These data reveal a myocardial deficiency of CoQ10, which is higher with increasing severity of disease and is reduced by therapy. This biochemistry correlates with the effective treatment of cardiomyopathy with CoQ10".

\section{The setting of sports and heat stress in daily life}

A personal experience of one of the authors (RM) at a triathlon competition resulted in a series of empirical observations relating heat stress and competitive sports. The temperature on the day of the venue was $34^{\circ} \mathrm{C}$ and raising. The local organizers included a longtime interval of 90 minutes between bike check-in and the start of the competition. Waiting under a hot ambient condition led to a situation of malaise and tiredness prior to any exertion. Physical achievement was reduced during the competition. After the event, a laboratory test revealed low CoQ10 levels. This empirical, subjective finding triggered our interest on CoQ10. Looking back at this situation one can say that the organizers did not follow the recommendation of the International Triathlon Union

Several press reports have added similar observations to this situation. The 2019 NYC Triathlon was cancelled due to heat. The running distance at the trial triathlon competition in Tokyo in August 2019 was shortened to only $5 \mathrm{~K}$ (instead of $10 \mathrm{~K}$ ) due to heat. The addition of heat and physical exertion still produced complications in some competitors. Local authorities and scientists in Japan have already looked at the problem of heat stress and exertion that can be expected to occur when the Olympic Games 2020 in Tokyo are underway $[113,114]$. Similar to the NYC triathlon day time variations and mechanical measures have been discussed for Tokyo 2020 [115]. While these are temperatures that exceed clearly ambient temperature, the addition of physical activity in the sense of exertional stress is also potentially related to damage. The world has witnessed the deleterious effect on female marathon runners in Doha, Qatar (September 2019). We can only speculate that CoQ10 and magnesium were consumed by both factors: humid heat and exertion. This would result in functional damage in ATP production as well as in Complex I function increasing ROS. We propose that these concepts should be considered by world athletic governing bodies in order to prevent physical damage. The 2020 marathon competition in Tokyo has now been scheduled to take place at a cooler setting in Sapporo, where the mean temperature is $5^{\circ}$ to $6^{\circ}$ lower than in Tokyo. Long distance $10 \mathrm{~K}$ swimming in open waters can have deleterious effects even at moderate temperature of $26^{\circ} \mathrm{C}$ [116]. While the main element is apparently the temperature, the component of physical exertion has to be considered. While the notion of CoQ10 and physical work is not new, previous studies have been based on concepts of oxidative stress damage [117]. Interactions between exercise and CoQ10 and other biomarkers have been described in the literature by Orlando et al. [118]. They observed an increase of CK and myoglobin while at the same time CoQ10 levels decreased following a 40 minute run at a level of $85 \%$ of maximal heart rate. Ubiquinol, the reduced form of CoQ10, produced a reduction of cytosolic ROS. The effect of CoQ10 on inflammatory changes and lactate in runners has been looked at by Armanfar [119]. Several biochemical parameters were unaffected (CRP, CK, blood lactate, IL-6, and TNF-alpha). The effect of combining body cooling and CoQ10 administration has also been investigated in the setting of elite swimmers. While pre-cooling showed no effects, there were beneficial effects of CoQ10 administration on cardiac damage markers, i.e. preventing a rise of CK-MB, cardiac Troponin I and myoglobin [120].

\section{Discussion}

When two diseases appear at the same time, it can be a casual or a causal condition. We consider that the case description presented by Kouzo [1], which led us to this analysis, should be taken as a condition that indeed describes related events. Based on our deductive analysis of the literature we propose that a heat shock reaction is the common pathophysiological event behind both entities. Our conceptual model of disease considers a disturbed function of Complex I of the OXPHOS respiratory chain to be the key event. Due to thermolability of CoQ10, the function of Complex I of the OXPHOS chain will be compromised resulting in ROS production and diminished ATP output. ATP is now considered to play a role in maintaining the solubility of proteins in the form of being a hydrotrope [121-123]. Following this concept, Sridharan et al. [124] have recently looked closely at the influence of ATP in maintaining protein structure showing important proteome wide interactions. On this basis it can be said that following protein denaturation due to heat, or other causes, low ATP levels will compromise the repair mechanisms of the chaperones of the heat shock response that require ATP. Altered solubility will involve the unfolded protein response. In a recent publication dealing with the closely related disease called peripartum cardiomyopathy, Karaye, Habib and Sliwa [125] declared that the early findings of Davidson [33], which that suggested a relation of heat to the heart failure situation "may not 


\section{Basic Clinical Biochemistry for Mitochondria and ER Function by Roy Moncayo and Helga Moncayo, WOMED, Innsbruck, Austria}

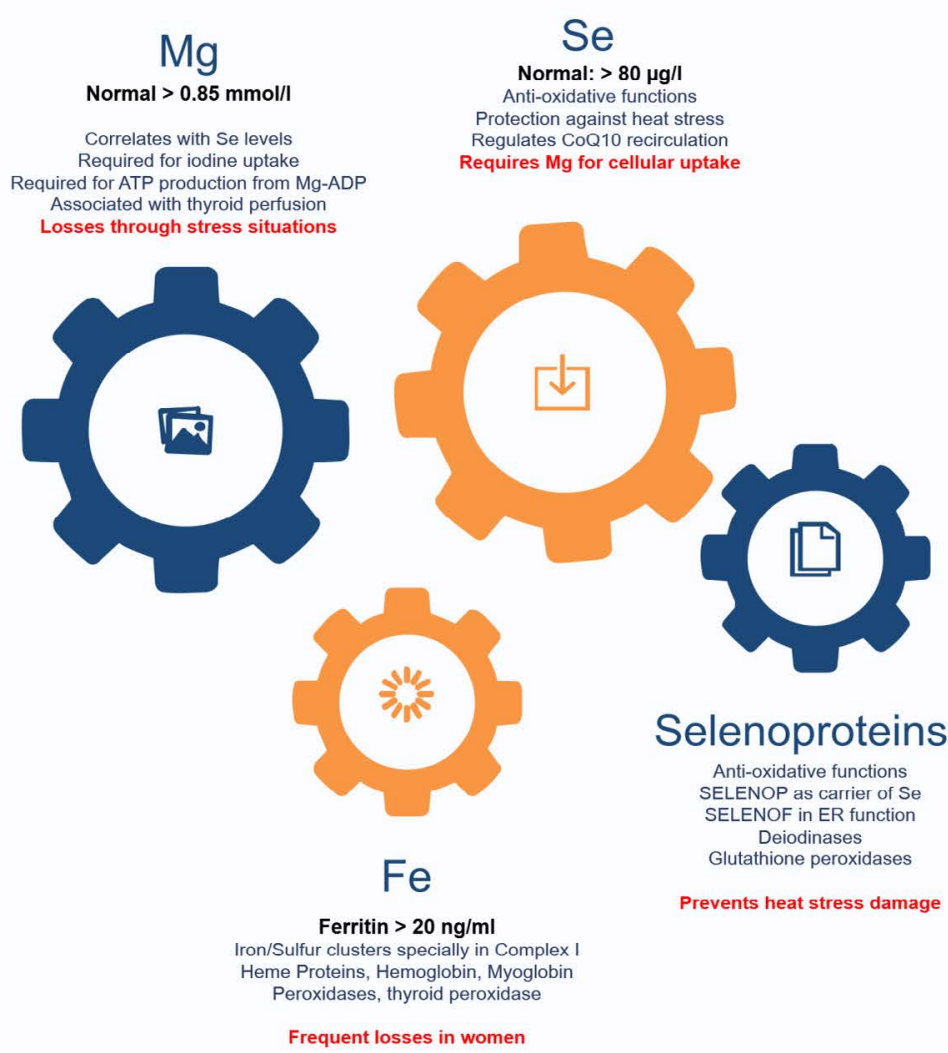

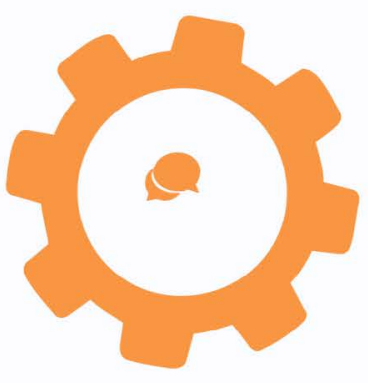

CoQ10 - Ubiquinone

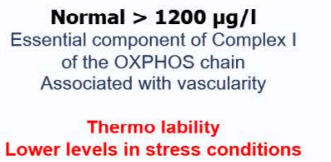

Endoplasmic Reticulum

Unfolded protein response requires ATP to function Requires contact to mitochondria (Mfn)

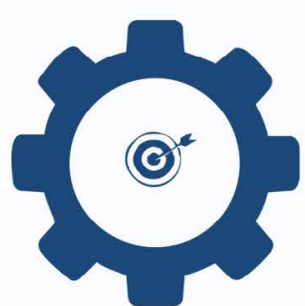

\section{Mitochondria}

ATP generation from Mg ADP Normal function prevents ROS generation Heat stress response

Figure 6. Basic biochemical elements for the maintenance of proteostasis together with mitochondrial and endoplasmic reticulum function.

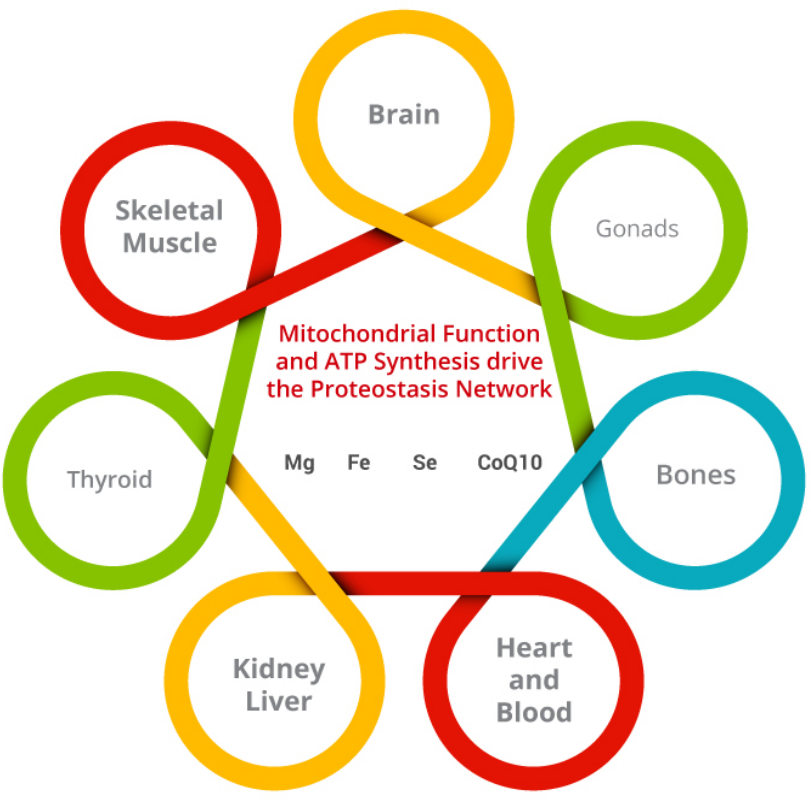

WOMED 2020 - Moncayo and Moncayo

Figure 7. Model of Shared Resources for the function of different organ systems. The physiological regulators of the distribution of magnesium, iron, selenium and Coenzyme Q10 have not been yet determined. Allowance of resources could depend on the level of metabolic activity, e.g. the brain and the heart 
Moncayo R (2020) Understanding the pathogenesis of peripartum heart failure in northern Nigeria based on interactions of external heat stress conditions with coenzyme Q10, selenium and magnesium - shared biochemical similarities with the pathogenesis of thyroid disease

be wholly responsible for the syndrome". Consequently, researchers engaged in the research of peripartum cardiomyopathy have neither looked at effects of heat exposure nor at cardiac proteostasis. The situation appears to be different for other cardiac affections. In the course of writing the final version of this manuscript we came across publications from the Department of Physiology, Amsterdam Cardiovascular Sciences related to cardiac proteostasis and the balance between endoplasmic reticulum and mitochondria, albeit from a different biochemical point of view [126,127]. On clinical grounds we consider that - the rather simple elements - magnesium, selenium and coenzyme Q10 are essential for proteostasis, Brundell et al. are focused on experiments related to the discovery of HSP-inducing compounds [128]. Despite these differences in the experimental design, the main concepts of proteostasis, heat shock response and endoplasmic reticulum function are being highlighted and discussed in cardiac research.

To conclude this review we will refer to the Editorial comment by Tremblay-Gravel and Pacheco who expressed their hope that research will help to identify therapeutic targets in PPCM and thyroiditis [2]. We can now hypothesize that the cardiac and thyroid disease described by Kouzu [1] have indeed a causal relation due to acquired functional changes of the mitochondria as we have previously described for thyroid affections $[6,18]$. We propose that the key target therapy candidates are magnesium, selenium and CoQ10 and iron. The pathogenesis chain starts with low magnesium which then leads to low selenium and low CoQ10 levels. These changes will impair the heat shock response resulting in decreased protection against heat stress. These biochemical elements should not be considered isolated from one another but rather as joint elements of the proteostasis process supporting mitochondrial function and consequently both the heat shock and the unfolded protein response (Figure 6). The model can be expanded to a condition of shared resources where supply to individual organs depends on their individual level of metabolic activity (Figure 7).

\section{Conflicts of interest}

The authors declare no conflicts of interest.

\section{Author's contributions}

$\mathrm{HM}$ and RM have developed the clinical working model and sonography methods. RM conducted the literature search and wrote the manuscript.

\section{References}

1. Kouzu H, Yano T, Nagano N, Koyama M, Ogawa T, et al. (2019) Postpartum Heart Failure Complicated with Thyroiditis: A Concealed Aggravator of Peripartum Cardiomyopathy? Can J Cardiol 35: 796 e1-796 e3. [Crossref]

2. Tremblay-Gravel M, Pacheco C (2019) The Thyroid Axis in Peripartum Cardiomyopathy: A Potential Contributor to a Multifaceted Disease. Can J Cardiol 35: 710-711. [Crossref]

3. Cénac A, Simonoff M, Moretto P, Djibo A (1992) A low plasma selenium is a risk factor for peripartum cardiomyopathy. A comparative study in Sahelian Africa. Int $J$ Cardiol 36: 57-59. [Crossref]

4. Moncayo R, Kroiss A, Oberwinkler M, Karakolcu F, Starzinger M, et al. (2008) The role of selenium, vitamin $\mathrm{C}$, and zinc in benign thyroid diseases and of Se in malignant thyroid diseases: low selenium levels are found in subacute and silent thyroiditis and in papillary and follicular carcinoma. BMC Endocr Disord 8: 2. [Crossref]

5. Moncayo R, Moncayo H (2007) A musculoskeletal model of low-grade connective tissue inflammation in patients with thyroid associated ophthalmopathy (TAO): the WOMED concept of lateral tension and its general implications in disease. $B M C$ Musculoskelet Disord 8: 17. [Crossref]
6. Moncayo R, Moncayo H (2015) The WOMED model of benign thyroid disease: acquired magnesium deficiency due to physical and psychological stressors relates to dysfunction of oxidative phosphorylation. BBA Clin 3: 44-64. [Crossref]

7. Moncayo R, Moncayo H (2015) Proof of concept of the WOMED model of benign thyroid disease: Restitution of thyroid morphology after correction of physical and psychological stressors and magnesium supplementation. BBA Clin 3: 113-22. [Crossref]

8. Karaye KM, Mohammed IY, Ogah OS, Okeahialam BN (2018) Rationale and Design for the Peripartum Cardiomyopathy in Nigeria (PEACE) Registry. Int Cardiovasc Forum J 12:12-17

9. Rabiu A, Garba I, Abubakar I (2016) Ritual hot bath (wankan jego) in Kano: Are they still practicing? What are the implications? Sahel Med J 19: 215-219.

10. Moncayo R, Moncayo H (2012) Advanced 3D sonography of the thyroid: focus on vascularity. In: Thoirs K, editor. Sonography: 273-292. Available from: Volume http:/ www.intechopen.com/articles/show/title/thyroid-sonography-in-3d-with-emphasis-onperfusion

11. Ritossa F (1962) A new puffing pattern induced by temperature shock and DNP in drosophila. Experientia 18: 571-573.

12. Waters E (2014) The mixed-up evolutionary history of the heat-shock proteins: Conservative innovation. Biochemist 36: 9-14.

13. Moncayo R, Moncayo H (2014) Exploring the aspect of psychosomatics in hypothyroidism: the WOMED model of body-mind interactions based on musculoskeletal changes, psychological stressors, and low levels of magnesium. Woman - Psychosom Gynecol Obstet 1: 1-11.

14. Moncayo R, Moncayo H, Kapelari K (2005) Nutritional treatment of incipient thyroid autoimmune disease. Influence of selenium supplementation on thyroid function and morphology in children and young adults. Clin Nutr 24: 530-531. [Crossref]

15. Freudenberger H (1974) Staff Burn $\square$ Out. J Social Issues 30: 159-165.

16. Moncayo R (2011) Reflections on the theory of "silver bullet" octreotide tracers implications for ligand-receptor interactions in the age of peptides, heterodimers, receptor mosaics, truncated receptors, and multifractal analysis. EJNMMI Res 1: 9 [Crossref]

17. Panossian A, Wikman G, Kaur P, Asea A (2009) Adaptogens exert a stress-protective effect by modulation of expression of molecular chaperones. Phytomedicine 16: 617622. [Crossref]

18. Moncayo R, Moncayo H (2017) Applying a systems approach to thyroid physiology: looking at the whole with a mitochondrial perspective instead of just TSH values or why we should know more about mitochondria to understand metabolism. BBA Clin 7: 127-140. [Crossref]

19. Lohmann K (1929) Über die Pyrophosphatfraktion im Muskel. Nat Sci 17: 624-625.

20. Drury AN, Szent-Györgyi A (1929) The physiological activity of adenine compounds with especial reference to their action upon the mammalian heart. $J$ Physiol 68: 213-37. [Crossref]

21. Burk RF, Hill KE, Motley AK (2003) Selenoprotein metabolism and function: evidence for more than one function for selenoprotein P. J Nutr 133: 1517S-1520S. [Crossref]

22. Crane FL, Widmer C, Lester RL, Hatefi Y (1959) Studies on the electron transport system. XV. Coenzyme Q (Q275) and the succinoxidase activity of the electron transport particle. Biochim Biophys Acta 31: 476-489. [Crossref]

23. Hendlin D, Cook TM (1960) The activity of coenzyme Q10 and its analogues in the succinoxidase system of electron transport particles. J Biol Chem 235: 1187-1191. [Crossref]

24. Choi JS, Park SY, Yi EY, Kim YJ, Jeong JW (2011) Coenzyme Q10 decreases basic fibroblast growth factor (bFGF)-induced angiogenesis by blocking ERK activation. Oncol Res 19: 455-461. [Crossref]

25. Nagase M, Yamamoto Y, Matsumoto N, Arai Y, Hirose N (2018) Increased oxidative stress and coenzyme Q10 deficiency in centenarians. J Clin Biochem Nutr 63: 129-136. [Crossref]

26. Stiban J, So M, Kaguni LS (2016) Iron-Sulfur Clusters in Mitochondrial Metabolism: Multifaceted Roles of a Simple Cofactor. Biochemistry (Mosc) 81: 1066-1080. [Crossref]

27. Webert H, Freibert SA, Gallo A, Heidenreich T, Linne U, et al. (2014) Functiona reconstitution of mitochondrial $\mathrm{Fe} / \mathrm{S}$ cluster synthesis on Isu1 reveals the involvement of ferredoxin. Nat Commun 5: 5013. [Crossref] 
Moncayo R (2020) Understanding the pathogenesis of peripartum heart failure in northern Nigeria based on interactions of external heat stress conditions with coenzyme Q10, selenium and magnesium - shared biochemical similarities with the pathogenesis of thyroid disease

28. Pandey A, Pain J, Ghosh AK, Dancis A, Pain D (2015) Fe-S cluster biogenesis in isolated mammalian mitochondria: coordinated use of persulfide sulfur and iron and requirements for GTP, NADH, and ATP. J Biol Chem 290: 640-657. [Crossref]

29. Xia L, Nordman T, Olsson JM, Damdimopoulos A, Björkhem-Bergman L, et al. (2003) The mammalian cytosolic selenoenzyme thioredoxin reductase reduces ubiquinone. A novel mechanism for defense against oxidative stress. J Biol Chem 278: 2141-2146. [Crossref]

30. Ritchie C (1849) Clinical Contributions to the Pathology, Diagnosis, and Treatment of Certain Chronic Diseases of the Heart. Edinb Med Surg J 72: 325-339. [Crossref]

31. Porak CD (1880) L'influence reciproque de la grossesse et del maladies du Coeur [thesis]. Medical Faculty of Paris, France.

32. Gouley BA, Mcmillan TM, Bellet S (1937) Idiopathic myocardial degeneration associated with pregnancy and especially the puerperium. Am J Med Sci 19: 185-199.

33. Davidson NM, Trevitt L, Parry EH (1974) Perpartum cardiac failure. An explanation for the observed geographic distribution in Nigeria. Bull World Health Organ 51: 203208. [Crossref]

34. Ezem BU, Otubu JA (1980) A complication of a traditional puerperal practice in Nigeria. Int J Gynaecol Obstet 18: 383-384. [Crossref]

35. Fillmore SJ, Parry EH (1977) The evolution of peripartal heart failure in Zaria, Nigeria. Some etiologic factors. Circulation 56: 1058-1061. [Crossref]

36. Ford L, Abdullahi A, Anjorin FI, Danbauchi SS, Isa MS, et al. (1998) The outcome of peripartum cardiac failure in Zaria, Nigeria. QJM 91: 93-103. [Crossref]

37. Mabogunje OA (1990) Ritual hot baths (wankan-jego) in Zaria, Nigeria. Newsl Inter Afr Comm Tradit Pract Affect Health Women Child: 10. [Crossref]

38. Antony KK (1980) Pattern of cardiac failure in Northern Savanna Nigeria. Trop Geogr Med 32: 118-125. [Crossref]

39. Iliyasu Z, Kabir M, Galadanci HS, Abubakar IS, Salihu HM, et al. (2006) Postpartum beliefs and practices in Danbare village, Northern Nigeria. J Obstet Gynaecol 26: 211215. [Crossref]

40. Isezuo SA, Abubakar SA (2007) Epidemiologic profile of peripartum cardiomyopathy in a tertiary care hospital. Ethn Dis 17: 228-33. [Crossref]

41. Saidu H, Kabir A, Ndiche N, Yau JA, Abdullahi Ut, et al. (2018) Prevalence and Characteristics of Peripartum Cardiomyopathy among Women with Cardiac Failure Referred for Echocardiography in a Tertiary Hospital in Northern Nigeria. $J$ Biosci Med 6: 95-104.

42. Ritossa F (1996) Discovery of the heat shock response. Cell Stress Chaperones 1: $97-$ 98. [Crossref]

43. Szent-Györgyi A (1957) Bioenergetics. New York: Academic Press.

44. Gabai VL, Kabakov AE (1994) Induction of heat-shock protein synthesis and thermotolerance in EL-4 ascites tumor cells by transient ATP depletion after ischemic stress. Exp Mol Pathol 60: 88-99. [Crossref]

45. Lindholm D, Korhonen L, Eriksson O, Koks S (2017) Recent Insights into the Role of Unfolded Protein Response in ER Stress in Health and Disease. Front Cell Dev Biol 5: 48. [Crossref]

46. Oikonomou C, Hendershot LM (2019) Disposing of misfolded ER proteins: A troubled substrate's way out of the ER. Mol Cell Endocrinol 500: 110630. [Crossref]

47. Haslbeck M, Weinkauf S, Buchner J (2019) Small heat shock proteins: Simplicity meets complexity. J Biol Chem 294: 2121-2132. [Crossref]

48. Yong J, Bischof H, Burgstaller S, Siirin M, Murphy A, et al. (2019) Mitochondria supply ATP to the ER through a mechanism antagonized by cytosolic $\mathrm{Ca}^{2}$. Elife 8: pii: e49682. [Crossref]

49. Trautinger $\mathrm{F}$ (2001) Heat shock proteins in the photobiology of human skin. $J$ Photochem Photobiol B 63: 70-77. [Crossref]

50. Richter K, Haslbeck M, Buchner J (2010) The heat shock response: life on the verge of death. Mol Cell 40: 253-266. [Crossref]

51. Laskowska E, Kuczyńska-Wiśnik D, Lipińska B (2019) Proteomic analysis of protein homeostasis and aggregation. J Proteomics 198: 98-112. [Crossref]

52. Marchi S, Patergnani S, Pinton P (2014) The endoplasmic reticulum-mitochondria connection: one touch, multiple functions. Biochim Biophys Acta 1837: 461-469. [Crossref]

53. Pobezhimova T, Voinikov V, Varakina N (1996) Inactivation of complex I of the respiratory chain of maize mitochondria incubated in vitro by elevated temperature. $J$ Therm Biol 21: 283-288.
54. Ludwig P, Bartels M, Schewe T, Rapoport S (1978) Selective inactivation of the NADH-ubiquinone segment of the respiratory chain of submitochondrial particles by endogenous free fatty acids during hyperthermia. FEBS Lett 95:181-184.

55. Kommuru TR, Ashraf M, Khan MA, Reddy IK (1999) Stability and bioequivalence studies of two marketed formulations of coenzyme Q10 in beagle dogs. Chem Pharm Bull (Tokyo) 47: 1024-1028. [Crossref]

56. Ide T, Tsutsui H, Kinugawa S, Utsumi H, Kang D, et al. (1999) Mitochondrial electron transport complex I is a potential source of oxygen free radicals in the failing myocardium. Circ Res 85: 357-363. [Crossref]

57. Zozina VI, Covantev S, Goroshko OA, Krasnykh LM, Kukes VG (2018) Coenzyme Q10 in Cardiovascular and Metabolic Diseases: Current State of the Problem. Curr Cardiol Rev 14: 164-174. [Crossref]

58. Seneș M, Erbay AR, Yilmaz FM, Topkaya BC, Zengi O, et al. (2008) Coenzyme Q10 and high-sensitivity C-reactive protein in ischemic and idiopathic dilated cardiomyopathy. Clin Chem Lab Med 46: 382-386. [Crossref]

59. Ranek MJ, Stachowski MJ, Kirk JA, Willis MS (2018) The role of heat shock proteins and co-chaperones in heart failure. Philos Trans R Soc Lond B Biol Sci 373: pii 20160530. [Crossref]

60. Iguchi M, Littmann AE, Chang SH, Wester LA, Knipper JS, et al. (2012) Heat stress and cardiovascular, hormonal, and heat shock proteins in humans. J Athl Train 47: 184-190. [Crossref]

61. Burk A, Timpmann S, Kreegipuu K, Tamm M, Unt E, et al. (2012) Effects of heat acclimation on endurance capacity and prolactin response to exercise in the heat. Eur J Appl Physiol 112: 4091-4101. [Crossref]

62. Stendig-Lindberg G, Moran D, Shapiro Y (1998) How significant is magnesium in thermoregulation? J Basic Clin Physiol Pharmacol 9: 73-85. [Crossref]

63. Sun LL, Gao ST, Wang K, Xu JC, Sanz-Fernandez MV, et al (2019) Effects of source on bioavailability of selenium, antioxidant status, and performance in lactating dairy cows during oxidative stress-inducing conditions. J Dairy Sci 102: 311-319. [Crossref]

64. Collier RJ, Doelger SG, Head HH, Thatcher WW, Wilcox CJ (1982) Effects of heat stress during pregnancy on maternal hormone concentrations, calf birth weight and postpartum milk yield of Holstein cows. J Anim Sci 54: 309-319. [Crossref]

65. Skibiel AL, Zachut M, do Amaral BC, Levin Y, Dahl GE (2018) Liver proteomic analysis of postpartum Holstein cows exposed to heat stress or cooling conditions during the dry period. J Dairy Sci 101: 705-716. [Crossref]

66. Christen F, Desrosiers V, Dupont-Cyr BA, Vandenberg GW, Le Francois NR, et al (2018) Thermal tolerance and thermal sensitivity of heart mitochondria: Mitochondrial integrity and ROS production. Free Radic Biol Med 116: 11-18. [Crossref]

67. Lutz A, Raina JB, Motti CA, Miller DJ, van Oppen MJ (2015) Host Coenzyme Q Redox State Is an Early Biomarker of Thermal Stress in the Coral Acropora millepora. PLoS One 10: e0139290. [Crossref]

68. Gagliano M, Dunlap WC, de Nys R, Depczynski M (2009) Ockham's razor gone blunt: coenzyme Q adaptation and redox balance in tropical reef fishes. Biol Lett 5: 360-363. [Crossref]

69. Stefely JA, Pagliarini DJ (2017) Biochemistry of Mitochondrial Coenzyme Q Biosynthesis. Trends Biochem Sci 42: 824-843. [Crossref]

70. Nakazawa H, Ikeda K, Shinozaki S, Yasuhara S, Yu YM, et al. (2019) Coenzyme Q10 protects against burn-induced mitochondrial dysfunction and impaired insulin signaling in mouse skeletal muscle. FEBS Open Bio 9: 348-363. [Crossref]

71. Stillman JH (2019) Heat Waves, the New Normal: Summertime Temperature Extremes Will Impact Animals, Ecosystems, and Human Communities. Physiology (Bethesda) 34: 86-100. [Crossref]

72. Bendahan D, Desnuelle C, Vanuxem D, Confort-Gouny S, Figarella-Branger D, et al (1992) 31P NMR spectroscopy and ergometer exercise test as evidence for muscle oxidative performance improvement with coenzyme $\mathrm{Q}$ in mitochondrial myopathies. Neurology 42: 1203-1208. [Crossref]

73. Sobreira C, Hirano M, Shanske S, Keller RK, Haller RG, et al. (1997) Mitochondrial encephalomyopathy with coenzyme Q10 deficiency. Neurology 48: 1238-1243. [Crossref]

74. Lalani SR, Vladutiu GD, Plunkett K, Lotze TE, Adesina AM, et al (2005) Isolated mitochondrial myopathy associated with muscle coenzyme Q10 deficiency. Arch. Neurol 62: 317-320. [Crossref] 
Moncayo R (2020) Understanding the pathogenesis of peripartum heart failure in northern Nigeria based on interactions of external heat stress conditions with coenzyme Q10, selenium and magnesium - shared biochemical similarities with the pathogenesis of thyroid disease

75. Rieske JS, MacLennan DH, Coleman R (1964) Isolation and properties of an ironprotein from the (reduced coenzyme Q)-cytochrome $\mathrm{C}$ reductase complex of the respiratory chain. Biochem Biophys Res Commun 15: 338-344.

76. Harika R, Faber M, Samuel F, Kimiywe J, Mulugeta A, et al. (2017) Micronutrient Status and Dietary Intake of Iron, Vitamin A, Iodine, Folate and Zinc in Women of Reproductive Age and Pregnant Women in Ethiopia, Kenya, Nigeria and South Africa: A Systematic Review of Data from 2005 to 2015. Nutrients 9: E1096. [Crossref]

77. Von Haehling S, Ebner N, Evertz R, Ponikowski P, Anker SD (2019) Iron Deficiency in Heart Failure: An Overview. JACC Heart Fail 7: 36-46. [Crossref]

78. Zhou X, Xu W, Xu Y, Qian Z (2019) Iron Supplementation Improves Cardiovascular Outcomes in Patients with Heart Failure. Am J Med 132: 955-963. [Crossref]

79. Toblli JE, Lombraña A, Duarte P, Di Gennaro F (2007) Intravenous iron reduces NTpro-brain natriuretic peptide in anemic patients with chronic heart failure and renal insufficiency. J Am Coll Cardiol 50: 1657-1665. [Crossref]

80. Hoes MF, Grote Beverborg N, Kijlstra JD, Kuipers J, Swinkels DW, et al. (2018) Iron deficiency impairs contractility of human cardiomyocytes through decreased mitochondrial function. Eur J Heart Fail 20: 910-919. [Crossref]

81. Paterek A, Mackiewicz U, Mączewski M (2019) Iron and the heart: A paradigm shift from systemic to cardiomyocyte abnormalities. J Cell Physiol 234: 21613-21629. [Crossref]

82. Mistry R, Hosoya H, Kohut A, Ford P (2019) Iron deficiency in heart failure, an underdiagnosed and undertreated condition during hospitalization. Ann Hematol 98: 2293-2297. [Crossref]

83. Cénac A, Simonoff M, Djibo A (1996) Nutritional status and plasma trace elements in peripartum cardiomyopathy. A comparative study in Niger. J Cardiovasc Risk 3: 483-4837. [Crossref]

84. Cénac A, Touré K, Diarra MB, Sergeant C, Jobic Y, et al. (2004) Plasma selenium and peripartum cardiomyopathy in Bamako, Mali. Med Trop (Mars) 64: 151-154. [Crossref]

85. Ejezie FE, Okaka AC, Nwagha UI (2012) Reduced maternal selenium levels in pregnant and lactating Nigerian women: should routine selenium supplementation be advocated? Niger J Med 21: 98-102. [Crossref]

86. Arroyo M, Laguardia SP, Bhattacharya SK, Nelson MD, Johnson PL, et al. (2006) Micronutrients in African-Americans with decompensated and compensated heart failure. Transl Res 148: 301-308. [Crossref]

87. Karaye KM, Yahaya IA, Lindmark K, Henein MY (2015) Serum selenium and ceruloplasmin in nigerians with peripartum cardiomyopathy. Int J Mol Sci 16: 76447654. [Crossref]

88. Karaye KM, Lindmark K, Henein MY (2017) Prevalence and predictors of right ventricular diastolic dysfunction in peripartum cardiomyopathy. J Echocardiogr 15 : 135-140. [Crossref]

89. Alehagen U, Johansson P, Björnstedt M, Rosén A, Dahlström U (2012) Cardiovascular mortality and $\mathrm{N}$-terminal-proBNP reduced after combined selenium and coenzyme Q10 supplementation: A 5-year prospective randomized double-blind placebo-controlled trial among elderly Swedish citizens. Int. J. Cardiol 167: 1860-1866. [Crossref]

90. Alehagen U, Alexander J, Aaseth J (2016) Supplementation with Selenium and Coenzyme Q10 Reduces Cardiovascular Mortality in Elderly with Low Selenium Status. A Secondary Analysis of a Randomised Clinical Trial. PLoS One 11: e157541. [Crossref]

91. Vadhanavikit S, Ganther HE (1993) Decreased ubiquinone levels in tissues of rats deficient in selenium. Biochem Biophys Res Commun 190: 921-926. [Crossref]

92. Vadhanavikit S, Ganther HE (1994) Selenium deficiency and decreased coenzyme Q levels. Mol Aspects Med 15: 103-107. [Crossref]

93. Zhang M, Wei J, Pan X, Shan H, Yan R, et al. (2013) Change of cardiac mitochondria STAT3 activity in rats with selenium deficiency and its relation with myocardial injury. Nan Fang Yi Ke Da Xue Xue Bao 33: 967-971. [Crossref]

94. Zhang C, Deng Y, Lei Y, Zhao J, Wei W, et al. (2017) Effects of selenium on myocardial apoptosis by modifying the activity of mitochondrial STAT3 and regulating potassium channel expression. Exp Ther Med 14: 2201-2205. [Crossref]

95. Xu J, Yin B, Huang B, Tang S, Zhang X, et al. (2019) Co-enzyme Q10 protects chicken hearts from in vivo heat stress via inducing HSF1 binding activity and Hsp70 expression. Poult Sci 98: 1002-1011. [Crossref]

96. Xu J, Tang S, Song E, Yin B, Wu D, et al. (2017) Hsp70 expression induced by CoEnzyme Q10 protected chicken myocardial cells from damage and apoptosis under in vitro heat stress. Poult Sci 96: 1426-1437. [Crossref]
97. Ren B, Huang Y, Zou C, Wu Y, Huang Y, et al. (2019) Transcriptional Regulation of Selenoprotein F by Heat Shock Factor 1 during Selenium Supplementation and Stress Response. Cells 8: E479. [Crossref]

98. Adamopoulos C, Pitt B, Sui X, Love TE, Zannad F, et al. (2009) Low serum magnesium and cardiovascular mortality in chronic heart failure: a propensity-matched study. Int J Cardiol 136: 270-277. [Crossref]

99. Birch RM, Walker GM (2000) Influence of magnesium ions on heat shock and ethanol stress responses of Saccharomyces cerevisiae. Enzyme Microb Technol 26 678-687. [Crossref]

100. Greenwald JH, Dubin A, Cardon L (1963) Hypomagnesemic tetany due to excessive lactation. Am J Med 35: 854-860. [Crossref]

101. Bouchama A (1995) Heatstroke: a new look at an ancient disease. Intensive Care Med 21: 623-625. [Crossref]

102. Bouchama A, Aziz MA, Mahri SA, Gabere MN, Dlamy MA, et al. (2017) A Mode of Exposure to Extreme Environmental Heat Uncovers the Human Transcriptome to Heat Stress. Sci Rep 7: 9429. [Crossref]

103. Barrientos A, Barros MH, Valnot I, Rotig A, Rustin P, et al. (2002) Cytochrome oxidase in health and disease. Gene 286: 53-63. [Crossref]

104. Racinais S, Moussay S, Nichols D, Travers G, Belfekih T, et al. (2019) Core temperature up to $41.5^{\circ} \mathrm{C}$ during the UCI Road Cycling World Championships in the heat. Br J Sports Med 53: 426-429. [Crossref]

105. Bi P, Williams S, Loughnan M, Lloyd G, Hansen A, et al. (2011) The effects of extreme heat on human mortality and morbidity in Australia: implications for public health. Asia Pac J Public Health 23: 27S-36. [Crossref]

106. Roselló-Lletí E, Alonso J, Cortés R, Almenar L, Martínez-Dolz L, et al. (2012) Cardiac protein changes in ischaemic and dilated cardiomyopathy: a proteomic study of human left ventricular tissue. J Cell Mol Med 16: 2471-86. [Crossref]

107. Lu D, Xia Y, Chen Z, Chen A, Wu Y, et al. (2019) Cardiac Proteome Profiling in Ischemic and Dilated Cardiomyopathy Mouse Models. Front Physiol 10: 750. [Crossref]

108. Ilievska G, Dinevska-Kjovkarovska S, Miova B (2018) Effect of single and repeated heat stress on chemical signals of heat shock response cascade in the rat's heart. Cell Stress Chaperones 23: 561-570. [Crossref]

109. Chen HB, Zhang XC, Cheng YF, Abdelnasir A, Tang S, et al. (2015) Association of heat shock protein 70 expression with rat myocardial cell damage during heat stress in vitro and in vivo. Genet Mol Res 14: 1994-2005. [Crossref]

110. Baljinnyam E, Hasebe N, Morihira M, Sumitomo K, Matsusaka T, et al. (2006) Oral pretreatment with ebselen enhances heat shock protein 72 expression and reduces myocardial infarct size. Hypertens Res 29: 905-113. [Crossref]

111. Wang JC, Chien WC, Chu P, Chung CH, Lin CY, et al. (2019) The association between heat stroke and subsequent cardiovascular diseases. PLoS One 14: e0211386. [Crossref]

112. Folkers K, Vadhanavikit S, Mortensen SA (1985) Biochemical rationale an myocardial tissue data on the effective therapy of cardiomyopathy with coenzyme Q10. Proc Natl Acad Sci U S A 82: 901-904. [Crossref]

113. Gerrett N, Kingma BRM, Sluijter R, Daanen HAM (2019) Ambient Conditions Prior to Tokyo 2020 Olympic and Paralympic Games: Considerations for Acclimation or Acclimatization Strategies. Front Physiol 10: 414. [Crossref]

114. Matzarakis A, Fröhlich D, Bermon S, Adami PE (2018) Quantifying Thermal Stress for Sport Events-The Case of the Olympic Games 2020 in Tokyo. Atmosphere 9: 479.

115. Kosaka E, Iida A, Vanos J, Middel A, Yokohari M, et al. (2018) Microclimate Variation and Estimated Heat Stress of Runners in the 2020 Tokyo Olympic Marathon. Atmosphere 9: 192.

116. Mountjoy M, Engebretsen L (2019) How sport and exercise medicine research can protect athlete health and promote athlete performance. Br J Sports Med pii: bjsports-2019-100749. [Crossref]

117. Díaz-Castro J, Guisado R, Kajarabille N, García C, Guisado IM, et al. (2012) Coenzyme Q (10) supplementation ameliorates inflammatory signaling and oxidative stress associated with strenuous exercise. Eur J Nutr 51: 791-799. [Crossref]

118. Orlando P, Silvestri S, Galeazzi R, Antonicelli R, Marcheggiani F, et al. (2018) Effect of ubiquinol supplementation on biochemical and oxidative stress indexes after intense exercise in young athletes. Redox Rep 23: 136-145. [Crossref] 
Moncayo R (2020) Understanding the pathogenesis of peripartum heart failure in northern Nigeria based on interactions of external heat stress conditions with coenzyme Q10, selenium and magnesium - shared biochemical similarities with the pathogenesis of thyroid disease

119. Armanfar M, Jafari A, Dehghan GR, Abdizadeh L (2015) Effect of coenzyme Q10 supplementation on exercise-induced response of inflammatory indicators and blood lactate in male runners. Med J Islam Repub Iran 29: 202. [Crossref]

120. Emami A, Tofighi A, Asri-Rezaei S, Bazargani-Gilani B (2018) The effect of shortterm coenzyme Q10 supplementation and pre-cooling strategy on cardiac damage markers in elite swimmers. Br J Nutr 119: 381-390. [Crossref]

121. Patel A, Malinovska L, Saha S, Wang J, Alberti S, et al. (2017) ATP as a biological hydrotrope. Science 356: 753-756. [Crossref]

122. Rice AM, Rosen MK (2017) ATP controls the crowd. Science 356: 701-702. [Crossref]

123. Meyer T, Voigt N (2017) In search for novel functions of adenosine 5'-triphosphate (ATP) in the heart. Cardiovasc Res 113: e59-e60. [Crossref]
124. Sridharan S, Kurzawa N, Werner T, Günthner I, Helm D, et al. (2019) Proteomewide solubility and thermal stability profiling reveals distinct regulatory roles for ATP. Nat Commun 10: 1155. [Crossref]

125. Karaye K, Habib A, Sliwa K (2019) Epidemiology of Peripartum Cardiomyopathy in Africa. Int Cardiovasc Forum J 15: 11.

126. Henning RH, Brundel BJJM (2017) Proteostasis in cardiac health and disease. Nat Rev Cardiol 14: 637-653. [Crossref]

127. Li J, Zhang D, Brundel B, Wiersma M (2019) Imbalance of ER and Mitochondria Interactions: Prelude to Cardiac Ageing and Disease? Cells 8: pii: E1617. [Crossref]

128. Van Marion D, Hu X, Zhang D, Hoogstra-Berends F, Seerden J-P, et al. (2019) Screening of novel HSP-inducing compounds to conserve cardiomyocyte function in experimental atrial fibrillation. Drug Des Devel Ther 13: 345-364. [Crossref]

Copyright: (C2020 Moncayo R. This is an open-access article distributed under the terms of the Creative Commons Attribution License, which permits unrestricted use, distribution, and reproduction in any medium, provided the original author and source are credited. 